\title{
SENSITIVITY ANALYSIS IN CELLULAR MANUFACTURING SYSTEM IN THE CASE OF PRODUCT MIX VARIATION
}

\author{
HAMID SEIFODDINI ${ }^{1}$, MANOOCHER DJASSEMI ${ }^{2}$ \\ ${ }^{1}$ Industrial and Manufacturing Engineering Department, The University of Wisconsin-Milwaukee, Milwaukee, WI, \\ ${ }^{2}$ Department of Industrial Studies, University of Wisconsin-Platteville, Platteville, Wisconsin
}

\begin{abstract}
In this paper, performance measures such as mean flow time and work-inprocess inventories will be used to determine the changes in the performance of a cellular manufacturing system due to product mix variations.
\end{abstract}

\section{INTRODUCTION}

Cellular manufacturing is used to overcome the deficiencies of hob shop manufacturing, including excessive setup times and high level of in-process inventories. In cellular manufacturing, part-families are identified and machine cells are formed such that one or more part-families can be fully processed within a single machine cell $[1,2]$.

A machine-part matrix which represents the processing requirements of parts in the product mix is the main source of data for the development of a cellular manufacturing system. As a result, product mix variations affect the structure of the machine-part matrix and the performance of the corresponding cellular manufacturing system $[5,6]$.

Generally, a cellular manufacturing system is designed based on a single machine-part matrix. When the product mix changes, the structure of the machine-part matrix representing the manufacturing system changes too. Since the cellular manufacturing system is designed to best fit the processing requirements of the original machine-part matrix, the new composition of parts in the machine-part matrix may adversely affect the system performance. While it is desirable to modify the cellular manufacturing system to meet the new processing requirements, for all practical purposes such a modification is not feasible. Therefore, it is necessary to foresee the changes in the product mix and to evaluate the performance of the cellular manufacturing system subject to these changes [8].

As a machine-part matrix deviates from its original structure, it is expected that the performance of the corresponding cellular manufacturing system deteriorates. Consequently, it is necessary to evaluate the performance of the cellular manufacturing system under these changes to determine the relationship between the percentage of changes of parts in the product mix and the rate of change in the performance. Such an evaluation is crucial in the decision making regarding the conversion from job shop to cellular manufacturing.

In this paper a procedure for the evaluation of the performance of a cellular manufacturing system under product mix variations will be presented. The procedure will be used to determine the sensitivity of the performance of a cellular manufacturing system to product mix variations. 


\section{DEFINITION OF THE PROBLEM}

A cellular manufacturing is designed to perform best for a specific product mix. When parts in the product mix or their production volume changes, the performance of the cellular manufacturing will change as well. Since in real world situations product mix variation is inevitable and it is not feasible to modify the cellular manufacturing system to fit the changes, it is necessary to determine the sensitivity of the performance of the cellular manufacturing system to such changes. To do so, the performance of the cellular manufacturing system should be evaluated under a range of possible compositions of parts in the product mix $[4,7]$.

Since the performance evaluation of any manufacturing system, particularly a cellular manufacturing system is complex, simulation modeling offers the best solution to the performance evaluation problem. Performance measures such as mean flow time and work-in process (WIP) inventories are widely used performance measures in the evaluation of cellular manufacturing systems. These two performance measures will be employed in this study.

\section{METHODOLOGY}

A simulation model of the cellular manufacturing system is developed and used to evaluate the performance of a cellular manufacturing system under product mix variations. The procedure for the performance evaluation can be summarized as follows:

1. Organize the manufacturing data in a machine-part matrix.

2. Develop a cellular manufacturing system based on the machine-part matrix in step 1.

3. Estimate the mean flow time and WIP inventories for the cellular manufacturing system using simulation modeling.

4. Repeat steps 1 through 3 for a range of product mixes.

This procedure can be used to establish a relationship between the performance of the cellular manufacturing system and changes in the product mix.

\section{ANALYSIS OF RESULTS}

A numerical example is used to demonstrate the procedure. The machine-part matrix for the manufacturing system is given in Figure 1. The demand for parts is assumed to be exponentially distributed while processing and setup times are deterministic. A detailed description of the model and the related data are given in [3].

Variations in the product mix have been introduced through changes in part types. Due to discrete nature of parts, the percentage of changes in the product mix are expressed in 0,6 , 13 , and $26 \%$. The percentage of change in the product mix is calculated as

$$
P=\frac{n}{N}
$$

where,

$$
\begin{aligned}
& \mathbf{P}=\text { percentage of change } \\
& \mathbf{n}=\text { number of part changes } \\
& \mathbf{N}=\text { total number of parts }
\end{aligned}
$$


PARTS

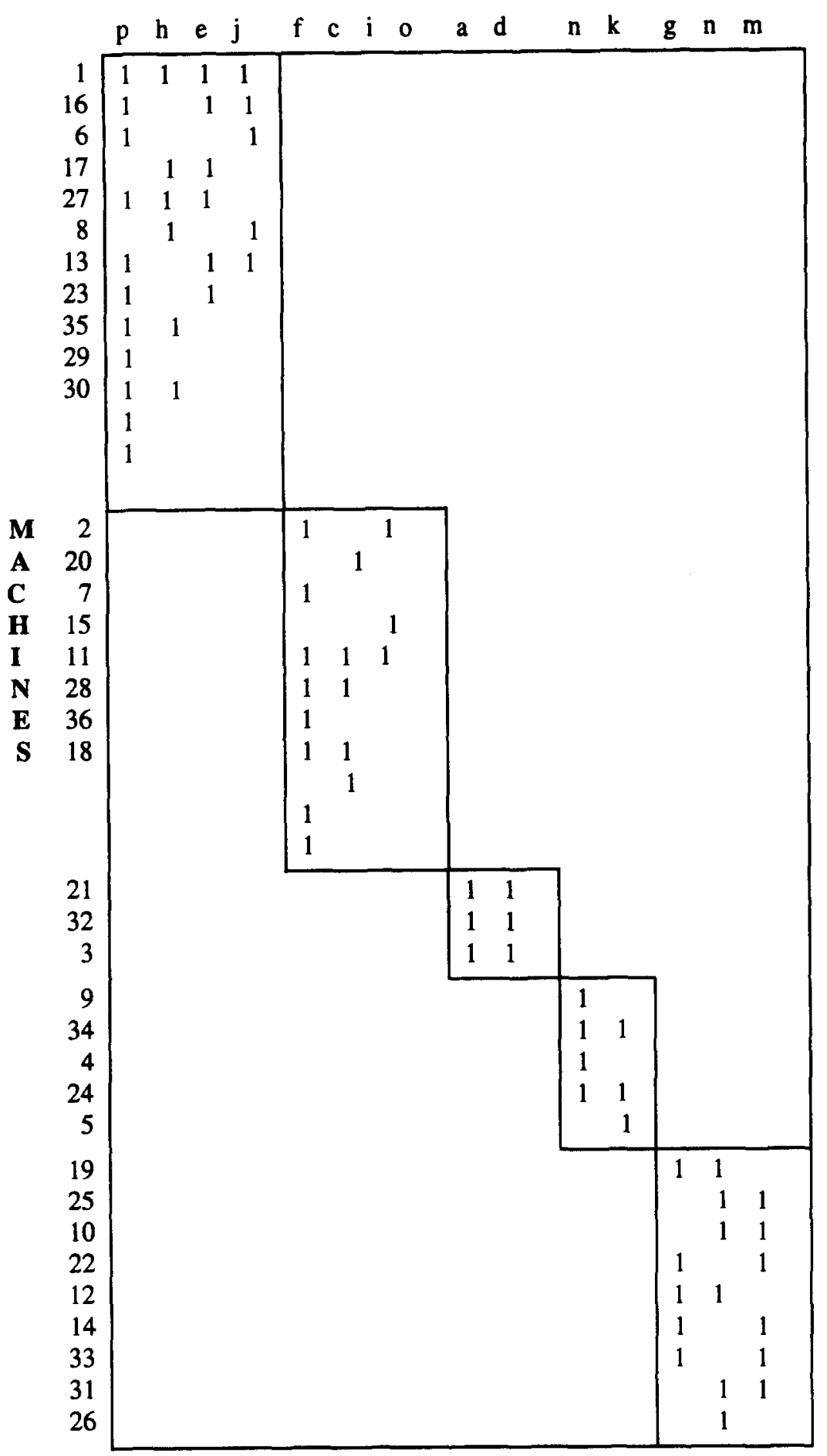

Figure 1. Machine-Part Matrix 
The machine-part matrices representing different product mixes are the main input to the simulation model. Estimates of the mean flow time and WIP inventories for the manufacturing system generated by the simulation model are given in Table 1 . As can be seen in this table as the percentage of changes in the product mix increases so do the mean flow time and WIP inventories.

Table 1. Simulation Results for Cellular Manufacturing Systems Under Product Mix Variations

\begin{tabular}{|c|c|c|}
\hline Product Mix Variations & Mean Flow Time & WIP Inventories \\
\hline 0 & 68.0 & .99 \\
6 & 74.0 & 1.19 \\
13 & 78.8 & 1.50 \\
20 & 90.9 & 1.82 \\
26 & 108.8 & 2.30 \\
\hline
\end{tabular}

The mean flow time for the original matrix (percentage of change $=0$ ) is 68.0 . It increases to 108.8 when the product mix changes $26 \%$. The changes in WIP inventories is even more dramatic (from .99 to 2.30 ) as the percentage of change in the product mix increases from 0 to $26 \%$. Therefore, the deviation from the original product mix in the machine-part matrix adversely affects the performance of the cellular manufacturing system.

\section{CONCLUSION}

The procedure presented in this paper provides a basis for the sensitivity analysis of the performance of a cellular manufacturing system under product mix variations. The simulation results show that changes in the product mix may lead to the deterioration of the performance of the system determination of the sensitivity of a cellular manufacturing system to product mix changes is an important step in the decision making about conversion from job shop to cellular manufacturing.

\section{REFERENCES}

1. Burbridge, J., "Change of Group Technology: Process Organization is Obsolete," Inter. J. Prod. Res., 30(5) 1209-1220 (1992).

2. Carrie, A., "Numerical Taxonomy Applied to Group Technology and Plant Layout," Inter. J. Prod. Res., 11(4) 399-416 (1973).

3. Djassemi, M., "The Use of Machine Grouping Efficiency in Comparison of Job Shop and Cellular Manufacturing Systems: A Simulation Study." Unpublished Ph.D. Dissertation, Department of Industrial and Manufacturing Engineering, University of WisconsinMilwaukee (1994).

4. Gupts, R. M. And Tompkins, J. A., "An Examination of The Dynamic Behavior of PartFamilies in Group Technology," Inter. J. Prod. Res., 20(1) 73-86 (1982) . 
5. King, J. R. And Nacornchai, V., "Machine-Component Group Formation in Group Technology: Review and Extension, Inter. J. Prod.Res., 20(2) 117-133 (1982).

6. McAulley, J., "Machine Grouping for Efficient Production," The Production Engineer, 52(2) 53-57 (1972).

7. Seifoddini, H. and Djassemi, M., "Selection of Machine-Component Charts for Cellular Manufacturing Based on Quality Index," Proceedings of 4th Industrial Engineering Research Conference, (1995).

8. Seifoddini, H., “A Probabilistic Model for Machine Cell Formation," Joumal of Manufacturing Systems, 9(1) 69-75 (1990). 